\title{
Organizational Challenges in the Public Sector. A Qualitative Study of the Swedish Armed Forces and Elderly Care
}

\author{
Pernilla Hoke Åberg \\ Swedish Defence University, Sweden
}

Elisabeth Arenö

Swedish Defence University, Sweden

\section{Aida Alvinius}

Swedish Defence University, Sweden

DOI: https://doi.org/10.18778/1733-8077.17.3.02

\section{Keywords:}

Organizational

Challenges; Public

Sector; Military;

Health Care;

Qualitative Study

\begin{abstract}
Society is continuously impacted by accelerating technical and social changes that challenge individuals, organizations, and societies. This appears to lead to the emergence of negative organizational behavior patterns that impose high levels of demands on employees. Firstly, the purpose of this study is to qualitatively examine how three organizational challenges-organizational anorexia, organizational greed, and organizational narcissism-are expressed in the Swedish public sector. Secondly, the Swedish Armed Forces and the field of elderly care are compared to discover additional organizational challenges by carrying out comparisons. The sample of organizations used is described in the Methods section. The study's main findings show that these three organizational challenges have been experienced in different ways in these organizations. A new organizational challenge has appeared, organizational temporality, describing participants' perceptions of time when carrying out their assigned tasks.
\end{abstract}

Pernilla Hoke Åberg has a Bachelor of Science in social analysis (Karlstad University, Sweden). She has been researching within the fields of media framing and military sociology organizational studies.

email address: pernilla.aberg@hoke.se

Elisabeth Arenö has a Bachelor of Science in social analysis (Karlstad University, Sweden). She has been researching within the fields of elderly care and organizational studies.

email address: lisa@addaction.se
Aida Alvinius has a Ph.D. (Karlstad University, Sweden). She is an Associate Professor and University Lecturer at the Department of Security, Strategy, and Leadership, Swedish Defence University, Karlstad and Stockholm, Sweden. She has published a number of articles, chapters in books, and research reports within the field of organization, collaboration and leadership, sociology of disasters, and military sociology.

email address: aida.alvinius@fhs.se 


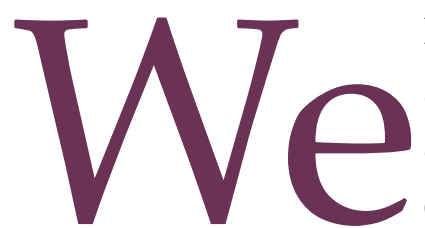

live in a time of accelerating technical and social changes (Bauman 2000; Giddens 2013; Rosa 2013) that challenge individuals, organizations, and societies. From an organizational perspective, these changes result in high levels of expectations imposed on organizational members and the organizations they belong to as they must constantly improve productivity in increasingly narrow timeframes. Due to these external and internal requirements, dysfunctional organizational behavior patterns appear (Rosa 2013; Alvinius, Johansson, and Larsson 2016). In organizational research, it appears that dysfunctional organizational behavior occurs continuously and is a result of a combination of environment, organization, people's cognitions, and their choices (Vaughan 1999). For example, Alvinius, Johansson, and Larsson (2016) have integrated three theoretical concepts that, in the public sector, organizations such as the Armed Forces, are perceived negatively. These are organizational greed, such as the demands imposed on employees and the balance between their work and leisure time; organizational anorexia, for example, cuts and resource reductions; and organizational narcissism, such as self-assertion and egocentrism. A similar theoretical integration of these concepts has not been posited in the civilian public sector context. Consequently, these three concepts form the point of departure for the continued analysis of the data collected.

The purpose of this study is twofold: a) to study how organizational anorexia, organizational greed, and organizational narcissism are expressed in the military organization and elderly care, and b) to gain a deeper understanding of other dark organizational characteristics in both organizations.

\section{The Context-The Swedish Armed Forces and Elderly Care}

In this section, we intend to explain our choice of organizations whose task is to deal with different types of stressful conditions in the public sector. The field of risk, crisis, and defense can be described through the causal chain threat-risk-crisis-crisis management-care-elderly care (Mellström 2010). This chain of events may be compared to the descriptions of how work is carried out before, during, and after an accident. This means that the risk, defense, and security sector is a male-dominated area and that the institutions that have to deal with the consequences of crises and accidents are, on the other hand, female-dominated, that is, healthcare, school, and care/treatment (Alvinius 2019). As a result, we have chosen to study organizations that are towards the two ends of the chain; the Armed Forces and elderly care. However, the focus is not gender. Both types of organizations handle different types of stressful conditions as their core task. The research gap identified concerns how they handle internal organizational strains. This is the primary reason for the choice of these two organizations. In the next paragraphs, the organizations are defined in more detail.

The Swedish Armed Forces is a government authority led by a Supreme Commander. The Authority is organized in various operational units plus a General Staff and Armed Forces Headquarters and operates in three branches; Air Force, Navy, and Army (Swedish Armed Forces ${ }^{1}$ ). The organization is hierarchically structured, meritocratic, and male-dominated (Alvinius, Ohlsson, and Larsson

\footnotetext{
1 See: http://www.forsvarsmakten.se/sv/sok/\#!/all?query=uppdrag. Retrieved October 10, 2017.
} 
2020). It is a complex organization, spread over large geographical areas, technologically advanced, and employs many different staff categories with varied educational levels and duties. The military task is dichotomized. On the one hand, the military is to develop and, if necessary, apply violence and, on the other hand, respect the norms of civilian society. The Swedish Armed Forces have been working for peace for a very long time, and the absence of war has impacted day-to-day operations. The organization operates in an institutionalized environment and is influenced by, and aligned with, other organizations. It is subject to many stipulations and regulations: from environmental requirements to gender issues to financial monitoring.

Elderly care can be described as a female-dominated activity with centralized control over resources and decentralized responsibility for execution. Primarily, the Social Services Act (SoL) and the Health Services Act (HSL) govern operations at the same time as unit managers must also comply with the Working Environment Act. Elderly care is defined as:

the part of the social services providing inputs for elderly people, both individually needs-tested and generally targeted. Housing in a particular type of accommodation, home care, and daycare are examples of individual, needs-tested inputs. Open activities are examples of general inputs. [SOU 2017:21² (trans. PHA, EA, AA)]

Care and treatment activities are relational and are based on a professional meeting between staff and the elderly person. According to the National Quality Plan for Care and Treatment of Older Persons

2 See: https://data.riksdagen.se/fil/F62427D9-5549-4467-802A988B954060C9. Retrieved May 22, 2021.
(SOU 2017:21), staff must have room for freedom of action to manage individual needs and cope with unexpected situations. To this end, the staff need preconditions consisting of training, supervision, and sufficient time.

\section{Organizational Dark Sides}

Organizational research is broad and interdisciplinary. A complementary perspective to existing research could be studying "the dark sides of the organization." To understand organizational challenges, we offer three different overall perspectives to use to observe and perceive the organization-the greedy, the narcissistic, and the anorexic. These have been summarized in previous studies to examine the contexts that affect organization members rather than the purely individual (Alvinius, Johansson, and Larsson, 2016; Ohlsson, 2020). The genesis of the concepts is, as mentioned, interdisciplinary and originates from sociology, psychology, and business administration, and together they offer a more holistic view of organizations and organizational behavior. However, knowledge is very limited in terms of how these organizational characteristics affect organizational life, its arrangement, and the ability to recruit capable staff. In addition, there are no studies that primarily focus on characteristics in different types of organizations-such as the male-dominated defense or the female-dominated elderly care. Reasonably, organizations implement these changes and demands from society to varying degrees and remain more or less greedy, anorexic, and narcissistic. Therefore, we have chosen the theoretical framework of these three organizational characteristics (greed, narcissism, and anorexia), which are initially deductively applied to interviews of staff from two selected organizations, and then also develop the underlying theoretical reasoning and note the 
difference. The starting point in this study can be said to adopt an abductive approach, which is specified in the article's methodological section. Below is an account of the three chosen concepts.

\section{Organizational Anorexia}

Anorexia concerns morbid self-starvation, and organizational anorexia deals with the cuts, resource reduction, and security risks associated with downsizing (Brännmark 2012). Theorell (2012) describes how one consequence of organizational anorexia is an imbalance between resources and tasks that may create stress for employees. For the individual, this may lead to long working days, shorter breaks, and, in the end, sick leave. Cutbacks concern all types of resource reduction: financial, time, material, and personnel. Radnor and Boaden (2004) use the terms "lean," "lean working," "leanness" to describe what is perceived as an anorectic organization. Organizational anorexia, according to Radnor and Boaden (2004), may be a consequence of organizational change, which leads to an inability to effectively utilize or balance the organization's resources.

\section{Organizational Greed}

Greed at the organizational level affects the domains of acquisition and the balance of rewards and demands between the employee and the organization. According to previous researchers (Coser 1974; Sullivan 2014; Alvinius, Johansson, and Larsson 2016; Ohlsson 2020), greedy institutions exemplify how individuals struggle to balance their freedom and the demands they experience from the various institutions and organizations they belong to. Coser (1974) describes that some organizations make very strong claims on their members and establish systems to enforce them. First, they seek exclusivi- ty and loyalty, and to achieve this, they act attractively. Second, they try to create an exclusive image and attempt to influence members to reduce ties to other competing organizations or individuals that may pose a threat to their loyalty. Third, members acquire strong affiliation and identification with the organization by creating a strong symbolic value for the organization. The exclusivity and extraordinary demands made by these organizations on their members make them greedy organizations, and boundless and manipulative behavior patterns are clear features of this. At the same time, the greedy organization weakens or even hijacks social ties to family and friends. The individual's relationship with the greedy organization must be exclusive and it cannot stand competition. Membership of a greedy organization causes conflict between family life and work life. Members feel that they have to make a considerable personal sacrifice to achieve balance. The roles of family life and work-life tend to be reversed and work offers stimulus and affiliation while the home is increasingly experienced as being a place with too much to do in too little time (Hochschild 1997; Watson 2003).

\section{Organizational Narcissism}

Several researchers have begun diagnosing organizations with narcissism. Grant and McGhee (2013) argue that narcissism derives from individuals with a strong belief in their superiority as compared with others and develops in an organizational culture seeking extra reward above all else. Organizational narcissism is most visible in the context around the leader, and from there, it gains a firm foundation in the organization (Grant and McGhee 2013). Blindness to unethical activity often occurs in the organization, and subordinates begin to mimic the behavior and unethical approach of the narcissistic leader, 
thereby normalizing behavior patterns and preserving the unhealthy culture. This narcissistic organizational behavior is harder to detect for outsiders (Rosenblatt and Sheaffer 2001; Alvesson and Spicer 2010). The narcissistic organization is characterized by an entitlement to exploit resources, employees, and other organizations. Organizations deny facts about themselves via spokespersons, propaganda, or campaigns. Rationalization allows organizations to develop a justification for their actions, decisions, and responsibilities. By expressing its uniqueness, its design, its status, and prestige the organization displays its grandiosity. Failures are blamed on external factors, and successes are explained by internal virtues, which means the organization shows the attribution of egotism. Finally, there is organizational anxiety, which in itself is not a mechanism that defends the ego but rather a mechanism for improving the ego (Brown 1997).

\section{Method}

The method used in this study is explorative and inductive with deductive elements. Consequently, empiricism governs the concepts and theoretical reasoning that are crystallized in the analysis. The results of the study are then explained with the help of previous research (Bryman and Bell 2015). This study is based on thematic analysis, and is mostly of an inductive, but partially of a deductive, nature. It is not uncommon for thematic analysis to be carried out both using an exploratory approach and driven by already existing theories (Clarke and Braun 2013; Bryman and Bell 2015), which is the case here. Thematic analysis is considered to be well used in behavioral science and in a number of other social science subjects. The method is very suitable for identifying codes, categories, and themes in a structured manner.
The chosen focus is a subjective social constructionist ontological perspective concentrating on the perceptions of the participants (Aspers 2011). We have explored descriptions in the experiences of each organization and conducted the study as a qualitative interview study. For interviewees to have the opportunity to make interpretations freely based on their experience and the organizational context, the interviews have been conducted using an open-ended interview guide and adapted follow-up questions (Aspers 2011). The following questions and themes were raised: a) background issues regarding professional experience, education, and skills, b) views of their organization, c) experience of self-centered organizations, cutbacks, and high levels of demands.

\section{Selection}

Interviews were conducted with individuals to gain a breadth of experience, background, age, and gender. Interviewees come from the Swedish Armed Forces and municipal elderly care. The selection of subjects in both organizations has been strategically based on the fact that we wished to interview managers at the middle-management level as they seem to experience cross pressure and are particularly vulnerable to demands both from the top and the bottom of the organization (Larsson et al. 2005). We have established contact with all our participants using the Snowball Principle (Esaiasson 2012 et al.) for their selection. Some through the Swedish Defence University (skills enhancement training) and some through previous contact networks. The Snowball Principle (Esaiasson et al. 2012) is defined as the request for interviews being made by asking the representatives of each organization whether they could recommend individuals who fit the study selection criteria. We got in touch with 
the study's first participant, who led to the next one through their recommendation. Before each interview, the participants received an information letter that included the purpose of the study, ethical aspects, and the main themes of the interview guides. All times and places were determined by the participants. The time required was set between 45-60 minutes. A total of seven people were included in the study, three interviewees in the field of elderly care (two women and one man from three different operations in the same municipality) and four active in the Armed Forces (two women and two men who represented different branches and organizations within the Armed Forces). A smaller number of interviews was, therefore, preferable. According to Bryant and Charmaz (2007:230), "the better data quality, the fewer number of interviews." As this model also complies with the principle of theoretical saturation (Glaser and Strauss 2017) and requirements for reliability and generalizability, we argue that seven interviews are sufficient to respond to the purpose and problem formulations.

\section{Data Collection and Analysis}

Five of the interviews have been conducted as telephone interviews due to hectic work schedules, and two as personal interviews held at the participant workplace and on Armed Forces premises. Interviews lasted 40-90 minutes. All interviews have been recorded (native language-Swedish) and transcribed verbatim. The coding and interpretation process was initiated inductively with open coding aimed at generating a variety of codes without taking into account the whole at that stage. Codes are the definition from which the material is structured and they may be related to the opinion of the actors, what is called first-order construction. Open coding is made to create overall meaning and provide an understanding of the written material (Aspers 2011; Glaser and Strauss 2017).

Thematic learning took place in a process where we searched for "meaningful devices" in the empirical data. After the material was coded, it was cut up and sorted according to the codes, thus beginning the creation of the thematicization of the codes. It should be mentioned here that all interviews were analyzed by all three authors to achieve inter-rater reliability (Bryman and Bell 2015).

One basic theme became the three dark organizational characteristics, and a new topic was found in the material after the inductive analysis. We, therefore, started from the existing theoretical concepts (anorexia, greed, and narcissism) and tested, using selective coding, whether they appeared in the data. The material that did not fit into existing themes was sorted as organizational temporality as different views concerning the time at work were very prominent in the organizations studied. Under each of the basic themes, we categorized sub-themes as and when they were generated from the data-subthemes such as "anorectic consistency" and "anorectic strategy." One example of how we coded is based on the following quote from an Armed Forces employee:

there are not enough people, I have so many different plates in the air that I need to work on with my staff, the same individuals need to be at two or three meetings at the same time and it is just not possible; of course, we do not try to divide the employees into working cells, but it just doesn't work. We have tried a few times, but it doesn't work.

This quote was coded as many employees need to be in multiple locations at the same time, and this catego- 
ry was sorted as an anorectic strategy. Then, we analyzed all the material submitted under each basic theme and continued the analysis by looking at the parts in relation to the whole and vice versa. The entire analysis process was based on the application of the hermeneutic circle, which means that the parts are understood in relation to the whole and vice versa (Aspers 2011).

\section{Results}

The analysis will be presented initially using organizational anorexia, followed by organizational greed, organizational narcissism, and organizational temporality, which is identified as a new organizational challenge perceived by the participants.

\section{Organizational Anorexia}

The analysis shows that the participants seem to experience signs of what is interpreted by the authors as anorectic organizational challenges within both the Armed Forces and elderly care. There are both similarities and differences in how this anorexia is expressed. Similarities include: a) imbalance between tasks and resources, b) time management, c) false economies, and d) security risks. Differences concern: a) loyalty and pride, b) management of newly-allocated resources, and c) lack of accommodation in elderly care. Below all these themes are presented in more detail.

\section{Imbalance between Tasks and Resources}

The fact that fewer people must do more is found as an anorexic expression in the analysis of both organizations. Similarly, fewer people are required to do more in less time. The Armed Forces show a markedly lower operational level that has been consistently reduced since the 1990s with the imbalance between resources and tasks as a consequence (Holmberg and Alvinius 2019). An interviewee gives the following description of cuts, explaining that it is a "triad" where time, tasks, and the number of staff interplay.

If we had the same staffing levels as we had about 10 years ago, then there would be no problem balancing time with work.

In elderly care, cutbacks are primarily described as rationalization regarding staff and scheduling. Cutting back on staff is described by an interviewee as the measure that has the greatest financial impact. Another strategy to solve financial challenges is that, in addition to direct staff reductions, work is transferred between groups to cut costs with the anorectic consequence that fewer people do more tasks. Another interviewee describes how cleaning assignments had been transferred to assistant nurses in an attempt to make savings.

You stop sending in the cleaners and then let the assistant nurses clean up instead. It could be an easy way to reduce your expenses.

\section{Time Management}

One consequence of resource reductions is that it often leads to overtime for existing staff and creates increased pressure on those remaining (Theorell 2012). In elderly care, it is sometimes stated that overtime becomes compulsory.

You might have to work over if something happens. You can't just go. Because they don't have such a long overlap. 
Organizational anorexia can lead to long working days, shorter breaks, and a culture where individuals feel that they have too much to do (Theorell 2012). One strategy described by an interviewee is schedules using split shifts.

You end up in situations such as having to work every other weekend or such long days you are off for three hours in the middle of the day. Then there will be changes in the schedule, and then it gets worse from a work environment perspective.

Within the Armed Forces, the participants' experiences can be interpreted as a strategy against anorexia. For example, the manager's task is to help their employees to prioritize when, for example, someone is to attend three meetings at the same time.

I assess which is the most important with those involved, which ones we have left as walkovers, and then I take the decision in dialogue with my colleagues.

The participants describe their frustration as the untouched job remains and must be done later. Priorities are made and reported upwards by the manager.

\section{False Economies}

Analyses of interviews from both organizations show how financial cuts can lead to strategies that, in turn, lead to additional costs even though the strategy was intended to manage financial cutbacks. In the field of elderly care, we see examples of false economies in terms of increased expenses as temporary staff must be employed for what regular staff did before. For example, accompanying a patient to a doctor's appointment is described by an interviewee.

If there were three of us there for a certain period, then you could do some things there, someone could go to the doctor, and there was a certain amount of room to maneuver.

Without this maneuvering room, the interviewee describes, what is not visible but still needs to be done occurs under conditions of greater uncertainty, causes more frustration, and is performed less flexibly. The fact that reductions mean that temporary workers must be deployed if necessary entails a lot of extra work for managers. "All extra recruitments that are not on the schedule are a lot of work," says one of the managers.

In the Armed Forces, the analysis shows how the increased pace due to financial tightening results in poor decision-making concerning, for example, purchases. The following shows that organizational anorexia leads to actions that ultimately lead to higher costs for the organization.

...and then we get material that we have not even asked for, does not fit into our operations, but everything has to happen so rapidly, someone stated authoritatively, "We need personnel carriers," and then a decision was taken, and that's not what we needed at all.

\section{Security Risks}

One consequence of cutbacks, which is similar in both elderly care and the Armed Forces, is that these reductions may create a riskier environment (Brännmark 2012). In the Armed Forces, OP (Officers' Program) students lack knowledge of, for example, core 
operations, which increases and poses challenges in practical terms when they are training. This knowledge gap could lead to erroneous decisions and greater risks for everyone involved. We illustrate.

...but when the cadets start working...they become leaders, and since they do not really have any confidence in implementing practical training, because that's what specialists do, they cannot lead the specialists in their operation...Many of them envisage that they will go straight from the officers' program to headquarters, and for someone to sit at headquarters and have no idea how core operations are conducted, and then make decisions about them, this will become apparent to the specialist officers who are on the line.

In elderly care, safety risks appear to increase for both staff and residents when cutbacks mean fewer employees taking care of more people with dementia and when some/several of these people do not get the support or care they need. For example, not being allocated accommodation that is adapted to your needs, but having to move around while waiting for the "right" accommodation, which one of the interviewees addressed.

[The negative consequences] are that everyone is moving around. Because you know that there is evidence that, especially for people with dementia and most elderly people have at least some kind of cognitive impairment, that for each relocation, you shorten their lives a little.

Organizational anorexia is also expressed in completely different ways in one organization without having an equivalent in the other. This may be because the organizations studied undertake such different tasks, and, consequently, resource cuts cause different results.

\section{Loyalty and Pride}

In both organizations, loyalty to purpose is expressed, even though resource reductions and changes create "change fatigue." From both organizations, expressions such as "We are loyal, and you do as much as you can" (Armed Forces) and "You just have to take care of people, and I think that all praise to the nurses and the assistant nurses, all this...they are doing so much good. So admirable" (elderly care).

On the other hand, there is a difference between staff and manager loyalty to their organizations. In the interviews with representatives of the Armed Forces, employees' approach to the organization appears to be pride in the purpose of the Armed Forces and its increased acceptance and legitimization in Sweden. Employees are trained to give everything and be loyal (Ydén 2008; Alvinius, Holmberg, and Johansson, 2019). One participant expresses the preparedness of the organization, and another highlights the broad-based general acceptance of the organization.

Yes, that's how great it is, it's happening quickly and easily, and lots of people have missed that we are, like, more legitimized somehow.

...and it feels like the Armed Forces once again have a broad basis in society, which is really to say I'm an officer and stand for that compared to before when I felt it was a bit more difficult.

Within elderly care, there seems to be loyalty to the difficult tasks that managers and employees struggle to find solutions to, but according to the interviewees' statements, there are a significant proportion of managers and employees within the organization 
who are neither proud nor particularly loyal. Wreder (2005) describes in her dissertation a similar duality in the view of employees. Statements from staff show exclusion of the "others." These "others" consist of staff described in negative terms because they do not perform their duties properly. Participants in this study express, among other things, disappointment and concern that some people seem to be tired of the profession and have lost focus on the fact that there are people to help.

I mean, do they not want the best for this person? Sometimes it sounds like I'd rather see the easy way out; medicate more. In that case, I think you have a responsibility to look for some other work.

\section{Management of Newly-Allocated Resources}

One difference is that there is no equivalent to the turnaround in recent years that has occurred in the Armed Forces in elderly care, with more resources beginning to flow in due to responsibility for overall defense and a new situation worldwide. However, cutbacks are still a factor that affects the organization to a considerable extent, according to the interviewees.

I think that somewhere at the beginning of the 2000s and maybe until 2012, 2013 it was very administratively heavy, while, as I now see it in the Authority, the pendulum has begun to swing back a little bit, that it has become more operations-related, and I think that this is connected to the increasing activity in our vicinity, they are waking up from their little nap in which they thought eternal peace was here to stay.

\section{Lack of Accommodation in Elderly Care}

In the care of the elderly, needs assessments are made for each individual, and then assistance inputs are assigned. A place in a residential home could be one of these inputs. An elderly care-specific consequence of cutbacks is the lack of residential homes and the difficulty in getting the right type of accommodation based on individual needs. An interviewee describes a chain reaction of relocations of elderly people who, due to accommodation shortages, are moved around to different accommodations such as "waiting-for-residence," "medical assessment" placement, and "short-term residence," until accommodation that suits the needs of the person becomes vacant.

Then you have moved from the hospital to the X-house, to the Y-bay, and the Z-hospital...so you understand how many moves it means.

The concept of creating needs-specific housing that has been implemented in $X$ municipality seems to be welcomed by the interviewees, but lack of space, unfortunately, results in many relocations, which is not good for elderly people and has consequences for the organization with increasingly confused individuals to be taken care of and acclimatized to new accommodation. An interviewee expresses this as follows:

It's such a big change, and it takes up to ten days to acclimatize to a reasonable level, and then maybe it's time to move again...I mean that if you are not already confused, this will make you confused.

\section{Organizational Greed}

Organizational greed is characterized by high levels of internal requirements or expectations, demands for availability, and commitment. The analysis shows that organizational greed exists in both the Armed Forces and elderly care and can be ex- 
pressed in both similar and different ways. There are more differences than similarities in organizational greed between the organizations; however, the common consequence is perceived stress. Similarities are: a) accessibility, b) overtime requirements, and c) demands from relatives. The differences are: a) requirements for adaptation to the outside world, b) requirements for academicization, c) demands for rapid processes, d) demands for physical exercise, e) meritocratic requirements, and f) emotional management demands in the care of the elderly.

\section{Accessibility}

There are modern technical tools such as e-mail and smartphones that make access easier and the balance between work and leisure may become blurred. In both the organizations analyzed, several interviewees expressed that there are expectations of being available via e-mail or telephone even outside of working hours. An interviewee from the Armed Forces describes the importance of clear guidelines and structures for managing accessibility requirements.

I want to say that it is very important that you, above all, from the manager's perspective, make it very clear to your employees that there is no need to respond to an email or a telephone call after working hours, unless you are on-call or your job means that you must apply a response time so to speak. Because it is easy to look at your mail and answer the phone even though it is an evening or weekend, and then we make a whip for our own back and our willingness to solve the problem is so strong that we may go too far and there will be staff burnout in the long run, which is not positive.

Even in elderly care, accessibility requirements are handled individually and in dialogue with employ- ees. One interviewee describes how clarity is central to managing accessibility requirements and exemplifies the fact that it is OK to contact if there are emergencies, but that you have confidence in the staff to solve more everyday events.

If it's really an emergency situation, I've said yes, OK, call me. So it is an emergency if someone has died, or if a staff member has died...If they call me to tell me they don't have enough staff, then I think, "solve it yourselves!"

\section{Overtime Requirement}

Overtime management is something that the interviewees from both elderly care and the Armed Forces expressed as a concern. Elderly care describes how overtime requests must be handled with care since, for many of the employees, free time is valued higher than extra pay. One interviewee says:

And you don't always want to, even if you get paid for it.

Within the Armed Forces, overtime is paid either with money or with leave. Like in elderly care, sometimes time is valued more highly than the money paid for overtime, and time off in lieu is experienced as difficult to utilize when diaries are so well-filled. The quote below describes opportunities for overtime management.

There should be a dialogue between the boss and the employer if you are going to take your overtime in cash or time and, without this dialogue, it will be the cash, but if you are not interested in money just now but want to have some time back, that's what is important, it's just not possible. 


\section{Demands from Relatives}

Demands from relatives are identified in different forms in both organizations. Requirements and expectations from the elderly person's relatives are something that the elderly care staff must deal with. These requirements may relate to how the staff manage the elderly person and the activities undertaken in the accommodation. An interviewee describes as follows:

It may be from relatives who think they own the care facility. They think they are entitled to determine the activities around their mum or dad. That's where we are, yes, it's clear they're going to join in, but where do the limits go? And how will we fix it so it is good for everyone? So you always feel a little bit unsure about how tough you can be.

The challenge for the staff is to relate to these requirements and to balance requirements from the employer, from the elderly person, and from their relatives, which, according to Coser (1974), characterizes organizational greed.

Within the Armed Forces, demands from another family group appear as examples. Here, it is the employee's family who is at the heart of the dilemma. The Armed Forces is one of the organizations identified as the greediest organization (Coser 1974) where demands concerning commitment and career are high level. One interviewee describes the understanding that comes from their boss on how to balance work and family life.

My boss is good, and he understands me when I say that everything has to work at home and then, like today, I sit at home and work because my husband is busy working all day and evening, and then I travel up tomorrow.
Within the Armed Forces, the analysis shows expressions of organizational greed that do not appear in elderly care. These are demands that are basically due to external factors that affect operations and organizational requirements. In the field of elderly care, we find factors that can be linked to the relational interpersonal professions, the emotional management that occurs in everyday practice.

\section{Requirements for Adaptation to the Outside World}

Over the last few decades, the Armed Forces have adapted their operations to conditions prevailing in civilian society (Ydén 2008). Such an adjustment is, for example, a more gender-equal view of parental leave. One interviewee states that the Armed Forces now compete for labor with other employers in a manner that has not previously been experienced and has consequently been forced to adapt, for example, as concerns parental leave. This adjustment leads to a conflict of claims on the employee in their balance between private and working life. On the one hand, you should take parental leave and, at the same time, work demands are piling up according to organizational traditions from when the organization was completely male-dominated, and parental leave was left to women (Ydén 2008).

\section{Requirement for Academicization}

Another adaptation to the civilian context that the Armed Forces have recently implemented is academicization and professionalization (Ydén 2008). Today, employees must have an academic education, but this education is perceived to have content that does not correspond to the competence objectives of what is considered by the interviewees as core operations-armed conflict and battle. 
I personally have quite a hard time with this academicization that is underway and it spills out over all operations just because those coming out of the OP [Officers' Program] are not really suitable for my world. They have not learned the right things and it's quite a long process to get them to actually function the way we want them to.

\section{Demands for Rapid Processes}

The analysis also shows examples of how the Armed Forces are affected by external environmental patterns such as rationalization and increased pace. It is about how processes take place much faster, with consequences such as poor decision-making and reduced quality. It is about demands concerning everything from how new employees are to be incorporated into operations to requirements to deliver rather than completing a task, or purchasing processes that lead to major purchase failures. One interviewee describes the situation as increased pace and reduced quality and that thoughtfulness could mitigate the situation.

This faster pace, it's a little bit about what I talked about before, doing everything so fast, for what benefit? Instead of making sure it's good...it feels like you care less about quality. There must be a result, and then we get shouted at when it does not turn out as it was supposed to, but if we had had the time to think twice, it would have been better.

\section{Demands for Physical Exercise}

Within the Armed Forces, employees are required to carry out physical exercise during working hours, and this is also linked to salary criteria. The analysis shows that there are challenges linked to this requirement for employees, as physical exercise must often take a step back to the benefit of other tasks and becomes deprioritized. Introducing physical exercise during working hours may in itself appear to be a generous act on behalf of the employer, but without the prerequisites for being able to implement it in relation to workload, a stressful situation arises for employees as they must match tasks and requirements. For the interviewee, this was not possible with a family and a long journey to the workplace.

This discussion that we are going to work out during working hours, but this often doesn't happen because there is so much else, and then you have to balance time with resources. Then physical exercise is also an assessment used for salary statistics...I protested because we complained that there was too much to do, how are we going to do this, too?

\section{Meritocratic Requirements}

The Armed Forces is a meritocratic organization, and the career system is clearly defined. This includes job rotation, which allows employees to move around the country with contract periods of a few years, there is an expectation that employees will work for some time at the headquarters in Stockholm and also carry out an international service period (Ydén 2008). The meritocratic system is something that the interviewers describe as part of the Armed Forces career and something that they must take a position on.

A typical example is that when we finish the higher staff education we are currently undertaking, we are expected, or at least we perceive the expectation, of a number of years working centrally at headquarters in some position, that's how it is. Even though it is not written in any law or order or in any directive any- 
where, it is felt that there is such an expectation by the organization.

\section{Emotional Management Demands in the Care of the Elderly}

Elderly care is a value-based activity and can be described as performing relational work with high-level demands on managing emotions during the course of daily activities (Olsson 2008). The analysis shows that the participants have to relate to the expectations of the residents, how they are doing that day, and their illnesses. The staff experience that they give a lot of themselves, and activities do involve emotional stress. One of the interviewees highlights the challenge of supporting and managing the feelings of the staff group while pursuing more strategic management work.

They live with the moods of these people. So the intrinsic feelings and what's happening day-to-day versus what I have to do and have to bring up to work with form a very difficult and challenging balance.

For some periods, operations are also carried out under time pressure that must be managed. No matter how stressful the situation is, the residents (and their relatives) must not experience this, states a head of the section. The manager is responsible for managing these stressful situations.

Yes, it is my responsibility, the treatment you receive when you come to us. That's really important. That you feel safe, regardless of whether it's crazy on the floor or not, you do not want to see a nurse running down the corridor. It is not possible. So you get [taking a deep breath], like this. Always be calm. Always be super calm and collected even when you are panicking inside. Otherwise, you will take them with you.
These two examples show how emotion management is present in the daily activities of elderly care and is something that the organization does not really have any preparedness or skills to handle. This is in line with previous research on emotional management in the care sector (Olsson 2008). In comparison with Armed Forces employees who, through education and socialization processes that clearly support emotion management, create a high level of collective trust between colleagues (Ydén 2008). Due to the lack of organizational support, emotional management in elderly care is challenging organizational greed that requires the individuals themselves to manage it or have the managers receive all these emotions.

\section{Organizational Narcissism}

Organizational narcissism can, to some extent, consist of a self-preservation function and may create a certain cohesion among organization members. However, in its extreme form, it may lead to several organizational problems. Similarities in organizational narcissism between the Armed Forces and elderly care are: a) hidden agendas, b) culture of silence, and c) grandiosity. The differences are as follows: a) moral dilemmas within elderly care and b) reorganization within the Armed Forces.

\section{Hidden Agendas}

Narcissism is individualized in both elderly care and the Armed Forces, but analysis shows that individuality is expressed in different manners. The Armed Forces reveal the fact that there are signs of narcissistic leaders with their agendas, their career is their focus, and almost everything circles around the leader oneself. At the organizational level, it is stated that there are individual agendas at different 
units which, according to one of the interviewees, may be due to unclear leadership, and that results in each unit primarily looking after its operations without taking the whole into account, which we interpret as an expression of the narcissistic organizational characteristics as stipulated by Brown (1997) and Grant and McGhee (2013). We illustrate.

Individual agendas at different units...in that there has been no clear leadership you can go in and pick out different people and tasks and it has not really coagulated with the overall defense approach of the Armed Forces.

From elderly care, one of the interviewees gives an example where they were to arrange with another manager to receive an elderly person who was to move into the facility. The interviewer found that it depended on which manager she met-one had the older person's best interests in focus, and the other had her agenda that governed her actions.

...usually, it depends on the person. Because it is people who interact with each other to try and fix this for the other person. And this is where there can be challenges sometimes...We are left with a person who is in the wrong place [unsuitable accommodation] because they do not really want to receive her/him at the right place.

\section{Culture of Silence}

The culture of silence means that you do not speak openly about perceived problems. In the Armed Forces, this culture expresses itself through the strong sense of loyalty that causes employees to bite the bullet and struggle to do the job. It is said that you "vent in the mess," but then you are back working on the task. An interviewee, for example, stated:
When I get annoyed about things, I let it all out in the mess and then carry on.

In elderly care, there are several examples of when the interviewees describe disassociated colleagues (individuals and groups) who avoid talking about problems. Here is an example from an interview:

From the healthcare assistant who thinks she is doing the world's best job to the boss who thinks he is doing the world's best job and then the whole organization upwards. And there is hardly any who dares to take up problems.

\section{Grandiosity}

One expression that organizational narcissism may take is grandiosity. This means that the organization, in an inflated, self-taught manner, emphasizes the uniqueness of its design, status, and prestige (Brown 1997). In the Armed Forces, the grandiosity of the organizational structure is reflected by the meritocratic system that contributes to high levels of status and prestige. This is experienced throughout the interviews with the Armed Forces representatives and their loyalty to the Armed Forces and their tasks, which is extremely high level. The self-image of the officer and the participant's image of the Armed Forces seem to be an expression of grandiosity and, despite the fact that the Armed Forces have adapted its operations to the structure of other authorities, the Armed Forces' special position remains, according to an interviewee.

So the Armed Forces must comply with the same requirements as other authorities, but it still has a special position because it is the ultimate guarantor in some way. 
In the field of elderly care, the grandiosity of the core operations is revealed in the relational aspect. Here, what resembles a martyrdom condition forms the front to grandiose behavior due to the lack of prestige and status, which forms the basis of the martyred grandiosity. Despite the lack of status and prestige (Wreder 2005), the operations produce something good with a high level of human value, and there seems to be pride and loyalty in the organization. One of the Heads of the Unit expresses their admiration for how co-workers struggle in spite of difficult challenges.

You just try to solve it [situation], it's like this, we're in the middle of this. You decide that this is what will happen this time only...but there's no point in asking, "How should we...?" You just take care of it, and I think that all the nurses and the assistant nurses deserve real praise, they manage so well. They are really admirable.

\section{Moral Dilemmas within Elderly Care}

The elderly care challenges associated with organizational narcissism concern ethical dilemmas. Whatever you choose must answer to the needs and interests of the person who is the subject of it. We thematized these into three types of dilemmas; in relation to elderly people/residents, to relatives, or to colleagues. A Head of the Unit told us about a typical moral dilemma that arises when the staff are forced to interact with a relative whose perception of a situation is different from the perception of the staff.

A moral dilemma, I think we encounter them almost every day. A lot in the staff management bit can deal with morality, what is happening at work, and we integrate with each other...But, then it may also be, "My mother is not getting out as much as she should do," even if...we have done it but...we experience the situation differently.

\section{Reorganization within the Armed Forces}

Organizational narcissism perceived within the Armed Forces concerns one aspect that is given in many different examples; reorganization and its consequences. The results show an organization that has become increasingly self-centered with a reduced holistic perspective.

It is clear that when you sit here in the middle of a reorganization and are busy with it, the Armed Forces in itself are more inward-looking when you keep on reorganizing or in your department, obviously, there are a lot of discussions around what is going to happen to the staff and with the jobs and everything.

\section{Organizational Temporality}

Another category appeared during the exploratory analysis, namely, organizational temporality. These are challenges seen from a time perspective and linked to everyday operations where the organization may not always be completely ready or possess sufficient knowledge to handle the emerging situation. Staff are not trained to deal with these challenges, but are sometimes forced to deal anyway. These include: a) when calm everyday operations become an emergency in elderly care and b) staff who are trained for fast, stressful conditions but must endure a calm, constant pace.

\section{Calm Everyday Operations Become an Emergency in Elderly Care}

In the field of elderly care, we interpret the participants' statements about emergencies as expressions 
of what we have termed a challenging tempo shift. Suddenly an emergency or extreme situation occurs, which must be rapidly dealt with. We illustrate.

When someone has two giant dogs or when someone lives in a druggy flat. This has happened to me, lots of their mates there all the time when we are going to help the person. Just because you get old, you don't necessarily become good [laughter]. Or, for example, I had a client who had a partner, a man, and we were supposed to help the woman, and the man was mentally unstable and had lots of knives all over the house.

\section{Staff Who Are Trained for Fast, Stressful Conditions Must Endure a Calm, Constant Pace}

Within the Armed Forces, the challenge is felt in a diametrically opposite manner. This is an organization whose driving force and core operations occur in a more emergency or extreme situation. Here, the organization is equipped for battle and confrontation. The Armed Forces' website describes their mission:

The main task of the Swedish Armed Forces is to be responsible for Sweden's military defense and to protect the country. We do this by carrying out operations and exercises around the clock, all year round, on the ground, in the air, and at sea. Whenever the need arises, the Armed Forces must be ready to act. [Swedish Armed Forces ${ }^{3}$ (trans. PHA, EA, AA)]

Over the last few decades, Sweden's external situation has been assessed as stable, and the Swedish defense has reduced focus on intervention opera-

3 See: https://www.forsvarsmakten.se/sv/om-forsvarsmakten/ darfor-finns-forsvarsmakten/vart-uppdrag/. Retrieved October 10, 2017. tions and increased administrative activities (Ydén 2008). Several interviewees testify to management operations and how employees do not find the situation satisfactory and feel that skills are being lost.

A soldier can never hang around and fester in a regiment, then they become a nobody. No soldier wants that, soldiers want to work, and, for them to work, they must either be on exercise or in action.

The consequence of this shift in pace, from slow to rapid and from rapid to slow, becomes what we call the fourth challenging organizational characteristic; organizational temporality. Tempo shifts occur in situations where preparedness levels are not high.

\section{Discussion}

The purpose of this study was to examine how organizational anorexia, organizational greed, and organizational narcissism are expressed in the Armed Forces and elderly care. The ambition was also to discover additional organizational challenges when comparing the two organizations. It may be noted that organizational narcissism, anorexia, and greed are perceived as occurring in the Armed Forces, as well as in elderly care. Organizational temporality also tends to express itself as a challenge, but is perceived differently.

There are similarities and differences between these organizations since they carry out different tasks, enjoy different statuses, and varying resource allocations in the public sector. The above is, therefore, an important theoretical contribution to organizational research, especially when the two, so different, organizations have been compared based on the threat-risk-crisis care and treatment scale (Mell- 
ström 2010). The challenges that have been studied may, however, affect the work environment and reduce well-being (Alvinius, Johansson, and Larsson 2016; Alvinius, Ohlsson, and Larsson 2020). A central task for managers at different organizational levels is, therefore, to deal with these dark sides to exercise the necessary damage control. Unhealthy work environment risks increase if the connection with organizationally negative aspects is not highlighted in these organizations. One conclusion of this study could be of a practical nature, namely, to recommend that newly-appointed managers examine and diagnose their organization and adapt their leadership styles to the prevailing situation.

Results confirm previous research on the position of the Armed Forces as the greediest organization (Coser 1974; Segal 1986), but when it comes to caring for the elderly, there is research that shows the presence of narcissism, but not that it was widespread throughout the organization (Kälvemark et al. 2004). Researchers (Coser 1974; Segal 1986; Ohlsson 2020) believe that a greedy organization exercises power over its members' legitimacy and attempts to maximize their loyalty by behaving attractively with high-level access to the organization's values and by creating different benefits. Results show that it appears positive for the organization to have loyal employees and may also be positive for employees. However, when the organization violates the privacy limit and the autonomy of the individual, it becomes a greedy organization, which causes the individual to have to parry different demands (Coser 1974). Both earlier research (Ydén 2008; Holmberg and Alvinius 2019) and this study show that the Armed Forces enjoy a very high level of loyalty built into the organization, which, in turn, contributes to organizational greed.
Organizational narcissism in elderly care tends to dominate. One reason may be that the participants experience a lower level of organizational loyalty in the care of the elderly, according to Coser's definition of greed. Loyalty to the task seems to be strong, however, society's view of the status of female- and male-dominated professions differs. Hence, also the allocation of resources and the degree of loyalty to the organization itself (Mellström 2010; Oscarsson and Danielsson 2018). Research in elderly care has previously highlighted the profession's low status (Wreder 2005), which may reinforce the argument for lower loyalty levels within elderly care. As we briefly described in the introduction, elderly care is characterized by decentralized management and employees with different types of qualifications. This may be regarded as an example of the heterogeneity of the organization as opposed to the more homogeneous Armed Forces with its clear structure of central governance and employees with similar qualifications. We consider that this heterogeneity in elderly care also influences the perception of the organization among its employees.

Based on this reasoning, we ask whether it may be the heterogeneity among employees in the elderly care organization that leads to lower levels of loyalty to the organization, which makes the properties of a narcissistic organization easier to attach. Narcissistic properties are often more disguised, according to Rosenblatt and Sheaffer (2001), and the high level of organizational loyalty within the Armed Forces may hide narcissistic properties, while the lower organizational loyalty in elderly care will make it visible.

We consider that the above reasoning on the impact of loyalty and whether and how the dark organiza- 
tional characteristics express themselves shows the importance of the organizational context. According to Larsson, Lundin, and Zander (2017), multiple contextual relationships (such as structure, regulations, power distribution, and culture) can affect leadership opportunities. These multiple patterns of different organizational and contextual factors influence leadership differently than one aspect alone. To create efficient operations, all organizations group their members. This is often to create an organizational home for everyone, but also to facilitate cooperation internally. The other organizational relationship that may affect leadership is the regulatory framework, that is, to what extent operations are governed by legislation and regulations. Higher degrees of regulations reduce the scope for local subcultures and self-government. We have seen examples of this in our analysis, that is, the effect of strong regulation in the Armed Forces while in elderly care there are legislation and guidelines that must be interpreted, which can lead to local subcultures. The third aspect that Larsson and colleagues presented deals with the distribution of power, the extent to which operations are centralized or decentralized.

In other words, the impact of the organizational context on leadership opportunities, as Larsson and colleagues (2017) describe, reinforces the relevance of this study's ambition of examining the existence of the three organizational challenges in a new organizational context.

The inductive analysis shows that the three organizational challenges can overlap when one challenge shifts character. The analysis showed, for example, that anorexia shifted over into greed based on how the participants in this study expressed their experience. Another result was entitled or- ganizational temporality and relates to shifts in pace and the preparedness of the participants in the organization for this tempo change in operations. We have highlighted two separate examples of this in our analysis and conclude that this is also an aspect that may be regarded as a challenging organizational feature.

This analysis is based on seven interviews, which may appear to be a small sample; however, the interviews have been analyzed and have resulted in a number of opinion-bearing units. To achieve greater generalizability, the intention is to quantify the study results in the organizations studied, and among several other professional groups in the public sector. For this study, whose purpose was to describe how these organizational challenges express themselves, these interviews may be enough. The study is qualitative and does not intend to generalize at present but describes the experiences presented in self-reported data. In addition to a survey, further research may be carried out based on a gender perspective and in a completely new context such as the Covid-19 pandemic, which appears to have affected local and global values. Results from this study can be used in educational settings in the organizations concerned. It is important to make both management and employees aware of these results to reduce any consequences that may arise from these organizational challenges. By drawing the attention of organizational members to the effect of these organizational dark sides, managers and employees may be able to focus on managing them. Otherwise, lack of insight can lead to scapegoating-everything is blamed on the individual without insight into how organizational structures and human actions are connected (Perrow 1978; Alvinius, Johansson, Larsson 2016). 


\section{References}

Alvesson, Mats and Andre Spicer. 2010. Metaphors We Lead By: Understanding Leadership in the Real World. London: Routledge.

Alvinius, Aida. 2019. "A Gender Perspective on Teachers as Crisis Managers." NORA-Nordic Journal of Feminist and Gender Research 27(2):125-138.

Alvinius, Aida, Arita Holmberg, and Eva Johansson. 2019. “Do Military Leaders Resist Organizational Challenges?" International Journal of Resistance Studies 5(1):34-60.

Alvinius Aida, Eva Johansson, and Gerry Larsson. 2016. “Negative Organizations: Antecedents of Negative Leadership?" Pp. 57-74 in Negative Leadership: International Perspectives, edited by D. Watola and D. Woycheshin. Kingston: Canadian Defence Academy Press.

Alvinius, Aida, Alicia Ohlsson, and Gerry Larsson. 2020. “Organizational Challenges and Leaders' Coping Strategies: A Qualitative Study of Swedish Military Staff Organization." Journal of Military Studies 9(1):24-33.

Aspers, Patrik. 2011. Etnografiska metoder: att förstå och förklara samtiden [Ethnographic Methods: To Understand and Explain the Present]. Malmo: Liber.

Bauman, Zygmunt. 2000. Liquid Modernity. Cambridge: Polity Press.

Brännmark, Mikael. 2012. Lean i kommuner och myndigheter: En översikt över existerande empirisk forskningslitteratur [Lean in $\mathrm{Mu}$ nicipalities and Authorities - An Overview of Existing Empirical Research Literature]. Retrieved May 22, 2021 (http://kth.diva-portal. org/smash/record.jsf?pid=diva2\%3A506798\&dswid=4349).

Brown, Andrew D. 1997. "Narcissism Identity and Legitimacy." Academy of Management Review 22(3):643-686.

Bryant, Anthony and Kathy Charmaz, eds. 2007. The Sage Handbook of Grounded Theory. Los Angeles, London, New Delhi, Singapore, Washington: Sage.

Bryman, Alan and Emma Bell. 2015. Business Research Methods. New York: Oxford University Press.

Clarke, Victoria and Virginia Braun. 2013. "Teaching Thematic Analysis: Overcoming Challenges and Developing Strategies for Effective Learning." The Psychologist 26(2):120-123.
Coser, Lewis A. 1974. Greedy Institutions: Patterns of Undivided Commitment. New York: Free Press.

Esaiasson, Peter et al., eds. 2012. Metodpraktikan: konsten att studera samhälle, individ och marknad [Method Practice: The Art of Studying Society, the Individual, and the Market]. Stockholm: Norstedts juridik.

Giddens, Anthony. 2013. The Consequences of Modernity. Stanford, CA: Polity Press.

Glaser, Barney and Anselm L. Strauss. 2017. Discovery of Grounded Theory: Strategies for Qualitative Research. London, New York: Routledge.

Grant, Patricia and Peter McGhee. 2013. “Organizational Narcissism: A Case of Failed Corporate Governance?" Pp. 97-109 in The Heart of the Good Institution, edited by H. Howard, G. Wijesinghe, and S. McKenzie. Dordrecht: Springer.

Hochschild, Arlie. 1997. The Time Bind: When Work Becomes Home and Home Becomes Work. New York: Metropolitan Books.

Holmberg, Arita and Aida Alvinius. 2019. "How Pressure for Change Challenge Military Organizational Characteristics." Defence Studies 19(2):130-148.

Kälvemark, Sofia et al. 2004. "Living with Conflicts-Ethical Dilemmas and Moral Distress in the Healthcare System." Social Science \& Medicine 58(6):1075-1084.

Larsson, Gerry, Josi Lundin, and Ann Zander. 2017. Ledarskapsmodellen: konsten att matcha individuella och organisatoriska förutsättningar [The Leadership Model: The Art of Matching Individual and Organizational Conditions]. Lund: Studentlitteratur.

Larsson, Gerry et al. 2005. "Indirect Leadership in a Military Context: A Qualitative Study on How to Do It." The Leadership E Organization Development Journal 26:215-227.

Mellström, Ulf. 2010. Genusvetenskapliga perspektiv på MSBs verksamhetsområden [Gender Scientific Perspectives on MSB's Areas of Activity]. Stockholm: Myndigheten för samhällsskydd och beredskap.

Ohlsson, Alicia. 2020. Adaptive Behaviors and Skills in High-Level Military Staff Work: Coping with Organizational Demands, Use of Smooth Power, and Political Skill. Doctoral Dissertation, Department of Psychology, Stockholm University. 
Olsson, Eva. 2008. Emotioner i arbete: en studie av vårdarbetares upplevelser av arbetsmiljö och arbetsvillkor [Emotions at Work: A Study of Care Workers' Experiences of the Work Environment and Working Conditions]. Dissertation, Karlstad University.

Oscarsson, Olof and Erna Danielsson. 2018. “Unrecognized Crisis Management-Normalizing Everyday Work: The Work Practice of Crisis Management in a Refugee Situation." Journal of Contingencies and Crisis Management 26(2):225-236.

Perrow, Charles. 1978. “Demystifying Organizations.” Pp. 105120 in The Management of Human Services, edited by R. C. Sarri and Y. Hasenfeld. New York: Columbia University Press.

Radnor, Zoe J. and Ruth Boaden. 2004. “Developing an Understanding of Corporate Anorexia." International Journal of Operations E Production Management 24(4):424-440.

Rosa, Hartmut. 2013. Social Acceleration: A New Theory of Modernity. New York: Columbia University Press.

Rosenblatt, Zehava and Zachary Sheaffer. 2001. "Brain Drain in Declining Organizations: Toward a Research Agenda." Journal of Organizational Behavior 22:409-424.
Segal, Mady W. 1986. "The Military and the Family as Greedy Institutions." Armed Forces \& Society 13(1):9-38.

Sullivan, Teresa A. 2014. "Greedy Institutions, Overwork, and Work-Life Balance." Sociological Inquiry 84(1):1-15.

Theorell, Töres, ed. 2012. Psykosocial miljö och stress [Psychosocial Environment and Stress]. Lund: Studentlitteratur.

Vaughan, Diane. 1999. “The Dark Side of Organizations: Mistake, Misconduct, and Disaster." Annual Review of Sociology 25(1):271-305.

Watson, Ian. 2003. Fragmented Futures: New Challenges in Working Life. Annandale: Federation Press.

Wreder, Malin. 2005. I omsorgens namn: tre diskurser om äldreomsorg [In the Name of Care: Three Discourses on Elderly Care]. Dissertation, Karlstad University.

Ydén, Karl. 2008. "Kriget" och karriärsystemet: försvarsmaktens organiserande i fred [The "War" and the Career System: The Organization of the Armed Forces in Peace]. Dissertation, University of Gothenburg.

\section{Citation}

Hoke Åberg, Pernilla, Elisabeth Arenö, and Aida Alvinius. 2021. “Organizational Challenges in the Public Sector. A Qualitative Study of the Swedish Armed Forces and Elderly Care." Qualitative Sociology Review 17(3):34-54. Retrieved Month, Year (http:// www.qualitativesociologyreview.org/ENG/archive_eng.php). DOI: https://doi.org/10.18778/1733-8077.17.3.02 